\title{
Fernando Namora e a pintura $^{1}$
}

\author{
Cláudia Ferreira \\ CEIS2O - Universidade de Coimbra
}

Resumo: Este texto detém-se na pintura de Fernando Namora, um ofício que nunca abandonou e que pese embora o recato, ao ponto de ser uma surpresa descobrir no escritor um pintor dedicado e autêntico, tem restado recolhida nas pregas do tempo. Primeiramente esclareceremos o/s nosso/s princípio/s, para depois indicarmos as obras que fazem parte da Colecção da Casa Museu Fernando Namora; no fim, que é dança, colocamos duas pinturas em diálogo: Estudo (1944/45) e Auto-retrato (1947).

Palavras-chave: pintura, escultura, masculino, feminino, dança

Abstract: This text discusses paintings by Fernando Namora, a craft he never abandoned although he kept it private. This aspect of his creative works has been virtually forgotten, to the extent that it is a surprise to discover the extent of his dedication and authenticity. First, we clarify our conceptual frame and then we present the set of paintings which are part of the collection of Casa Museu Fernando Namora; Finally, through dance, we experiment a dialogue between two of his works: Estudo/Study (1944/45) and Auto-retrato/Self-portrait (1947).

Keywords: painting, sculpture, masculine, feminine, dance

\section{Princípio/s}

Vimos escrevendo sobre a pintura de Fernando Namora desde o volume no 3 , publicado em 2016, da revista Algar, a da Casa Museu Fernando Namora e que corresponde, esta casa, ao lugar exacto onde nasceu o escritor e pintor; passando por 2018, volumes $\mathrm{n}^{\mathrm{O}} 4 / 5$, e até $2019, \mathrm{n}^{0} 6$, coincidente, este último, com o centenário relativo 
ao nascimento de Fernando Namora. Desde o início procuramos nortear-nos por alguns princípios que consideramos também critérios de justiça, tomando como sério o pressuposto de Roland Barthes quanto à postura crítica.'

Julgamos importante enunciá-los agora, e aqui, claramente.

Assim, temos procurado não ensimesmar a pintura de Fernando Namora, precisamente "nela própria”, o que pode parecer equívoco e significa contrariar essencialmente duas posturas: não periodizar a totalidade da obra subsumindo-a, assim, na História da Arte; não encastrar derradeiramente a expressão da sua pintura numa “expressão máxima”, como seja o Neo-Realismo, por exemplo. 0 ensimesmamento a que nos referimos resulta, sobretudo, o que pode parecer paradoxal, de pontos de vista que comportam uma externalidade relativa à obra; o nosso esforço foi sempre, então, no sentido de manter a atenção num movimento interior/interno à própria obra para, de dentro, fazer sobressair a intensidade inerente à pintura namoriana. Talvez seja interessante rememorar o percurso calcorreado: não fazendo um resumo propriamente, mas tentando clarear as problemáticas desenvolvidas.

Primeiramente, para que nos pudéssemos situar, tivemos necessidade de fazer uma aproximação à pintura de Fernando Namora no sentido de criar afinidades electivas, por um lado, e, por outro, particularizar o que nos parecia ser o selo do seu legado pictórico. Assim, se para as primeiras encontrámos veios condutores entre Fernando Namora e Amadeo de Souza-Cardoso, Eduardo Viana, Dominguez Alvarez e Julio; já no que respeita à singularidade registámos três realidades: a terra, a árvore e o sentido escultórico na sua pintura. Tal entendimento foi de certa forma inaugural, servindo de ordenador, tanto visual como analítico. Registe-se que não se estabeleceu uma grelha de onde poderiam emergir leituras mais ou menos programadas, mas estabiliza-se de alguma forma o olhar ao serem criados alguns princípios ordenadores. Tais princípios seriam, e continuarão a ser, os responsáveis por se estabelecerem relações comunicantes nos estudos que foram, e venham a ser ainda, prosseguidos.

Assim, no segundo e terceiros momentos detivemo-nos em duas obras concretas, Estudo, primeiro, e Auto-retrato, depois: o feminino, e as mulheres por inerência, visto/vistas por Fernando Namora, bem como a identidade, reflexa. Em ambos os casos, o nosso esforço foi sempre o de tomar as obras em mãos como espécies de sintomas, dando corpo à "iconologia do intervalo" que Aby Warburg preconizou, conformadora da sua "ciência sem nome" e que concorre para aquilo a que chamou de "antropologia da cultura ocidental”, como Giorgio Agamben deixa manifesto de forma sintética e eficaz. ${ }^{2}$

O nosso intuito, sem localizar com precisão o que fazemos do ponto de vista disciplinar, como Aby Warburg viu, e bem, todavia, não passa por deixar as obras de arte numa espécie de "terra de ninguém”: apesar de "ciência sem nome”, estamos conscientes, como o frisou Walter Benjamin, da energia que irradia do nome, ${ }^{3} \mathrm{da}$ imperiosa necessidade de nomearmos. Por tal, sempre quisemos inscrever a obra pictó- 
rica de Fernando Namora, pese embora, não a dando a ver a partir de ângulos talvez mais expectáveis. Na verdade, as obras, do ponto de vista da crítica, permaneciam numa terra não revolvida: existiam esparsas valorações, bastante marcadas por sentimentos de admiração pessoal e amizade, bem como uma inaugural categorização formal, enunciada em termos de periodização. ${ }^{4}$ Não querendo repetir o que estava feito, nem sequer transformá-lo em semeadura que continuássemos, entendemos que seria estimulante ensaiar diferentes perspectivas, concordantes com os princípios antes enunciados.

Nesta sede, e após termos clareado este/s princípio/s, concentrar-nos-emos brevemente nos lugares e nos rostos de Fernando Namora, para, com outro fôlego, seguirmos o seu "rio de pintura".

\section{Os lugares e os rostos}

No que a Fernando Namora respeita, como já se viu bem, o “itinerário de uma vida” verteu-se na "geografia de uma obra" : o médico que se deixou marcar a ferro e fogo pela palavra, mas que também a inaugurou, e é o escritor que o mundo conhece, sorveu com olhos ávidos o que o circundava e estabeleceu um trilho pictórico dos lugares. Vale Florido, Rabaçal, Coimbra, Monsanto, Pavia, Lisboa e imediações: as estações da sua viagem insone, a proporcionarem, hoje também, um sonambulismo a que se torna impossível virarmos o rosto. Já o repetimos, em face da circunstância de Fernando Namora se conceber como um "pintor dos domingos” (Namora 1998: 26), marcando-se mesmo um compasso de espera quanto à imersão analítica, mas sensível, no seu legado visual: “cabe-nos tornar 'artísticas' obras pictóricas que o próprio cobriu de pudor?” (Ferreira 20ı8: 21-22). Feito o nosso acto de contrição, cuja boa-nova foi aliás auxiliada por palavras do escritor-pintor - "há sempre uma ou outra particularidade das nossas obras que apenas os alheios captam. É a clássica história das árvores que não deixam ver a floresta" (Namora 1998: 62): avançámos, e avançamos ainda.

Concentramo-nos agora nas obras pertencentes à Colecção da Casa Museu Fernando Namora: incluem pedaços de Monsanto, Pavia, Ericeira e Lisboa, e rostos. Enumeremo-las, por ordem cronológica: Retrato de Joaquim Ferrer, 194I, óleo; Estudo, 1944/45, óleo; Pintura Raiana - Monsanto, 1945, óleo; Paisagem de Monsanto sobre o Tejo, 1956, óleo; Casario de Monsanto, 1956, óleo; Vista de Pavia, anos 50, óleo; Árvores, 1964, óleo; Guindaste no Porto de Lisboa, 1967, óleo; Paisagem, 1972, óleo; Retrato de José Manuel Mendes, anos 80, óleo, obra inacabada. Pela enumeração rapidamente se percebe o sentido com que Rui Jacinto abre a versão escrita do projecto "Fernando Namora: Itinerário de uma Vida, Geografia de uma Obra”, incluído na programação das Comemorações do Centenário do Nascimento do escritor(-pintor): "A vida vivida contaminou a obra de Fernando Namora com marcas indeléveis que evidenciam uma estreita correlação entre o percurso multiterritorial do homem e os diferentes ciclos de um itinerário criativo” (Jacinto 2019: II). Assim na ventura literária, assim na a-ventura pictórica. 
Nascido em Condeixa-a-Nova a 15 de Abril de 1919, onde fez a Instrução Primária, daqui passaria a Coimbra, onde frequentou o Colégio Camões, com breve incursão pelo Liceu Camões em Lisboa, daí retornado para se matricular no Liceu José Falcão, novamente em Coimbra, cidade onde viria a concluir o curso de Medicina, concretamente no ano de 1942. Depois: consultório em Condeixa, no mesmo ano; 1943 - TinaIhas, próximo de Castelo Branco, cidade onde faz, em 1944, a primeira e única mostra de pintura individual; 1945 - Monsanto; 1946 - é médico municipal em Pavia, Alentejo; 1949 - participa, em Paris, numa exposição internacional de artistas plásticos; 1950 admitido como assistente no Instituto Português de Oncologia, em Lisboa.

Ao confrontar-se a datação das obras enunciadas com o percurso de seguida fixado, rapidamente se manifestam as coincidências: os lugares e os rostos enunciam o caminho de Fernando Namora. Uma excepção: Estudo.

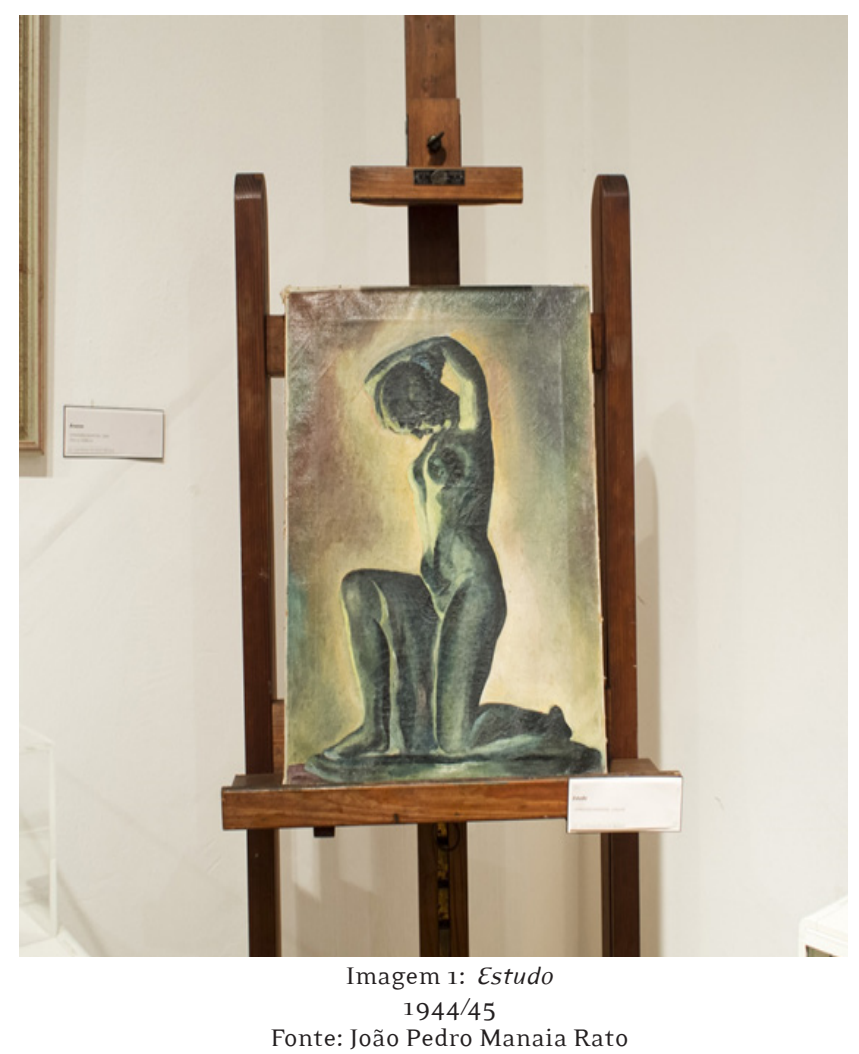




\section{0 "rio de pintura"}

Podemos afirmar que Fernando Namora não reservou a mão que pintava ao taThe de figuras no feminino: além de Estudo e de um retrato de Zita, a segunda muIher, não se conhecem exactamente outras obras que nesse talhe se detenham. Todavia, em termos do seu "labor literário" (Lisboa 1999: 131) deixou-nos personagens de complexidade inegável, tanto claras, cristalinas, como se fossem feitas de água, mas também dilemáticas, dilaceradas, de corações habitados pela antracite. Embora não neguemos a acutilância devida ao cruzar dos ambientes da sua pintura com as obras literárias, não tencionamos fazê-lo: o que em parte se relaciona com a resistência em criar um sistema auto-referencial, mas também porque reconhecemos faltar-nos conhecimento aprofundado das zonas literárias namorianas, aquele que permitiria estabelecer solidamente as relações de facto criativas. Como quem se confessa não merece castigo, tal qual o senso comum no-los confirma, passamos a encetar um diálogo entre Estudo (imagem 1) e Auto-retrato (imagem 2) ou entre o feminino e o masculino, ou entre a escultura e a pintura.

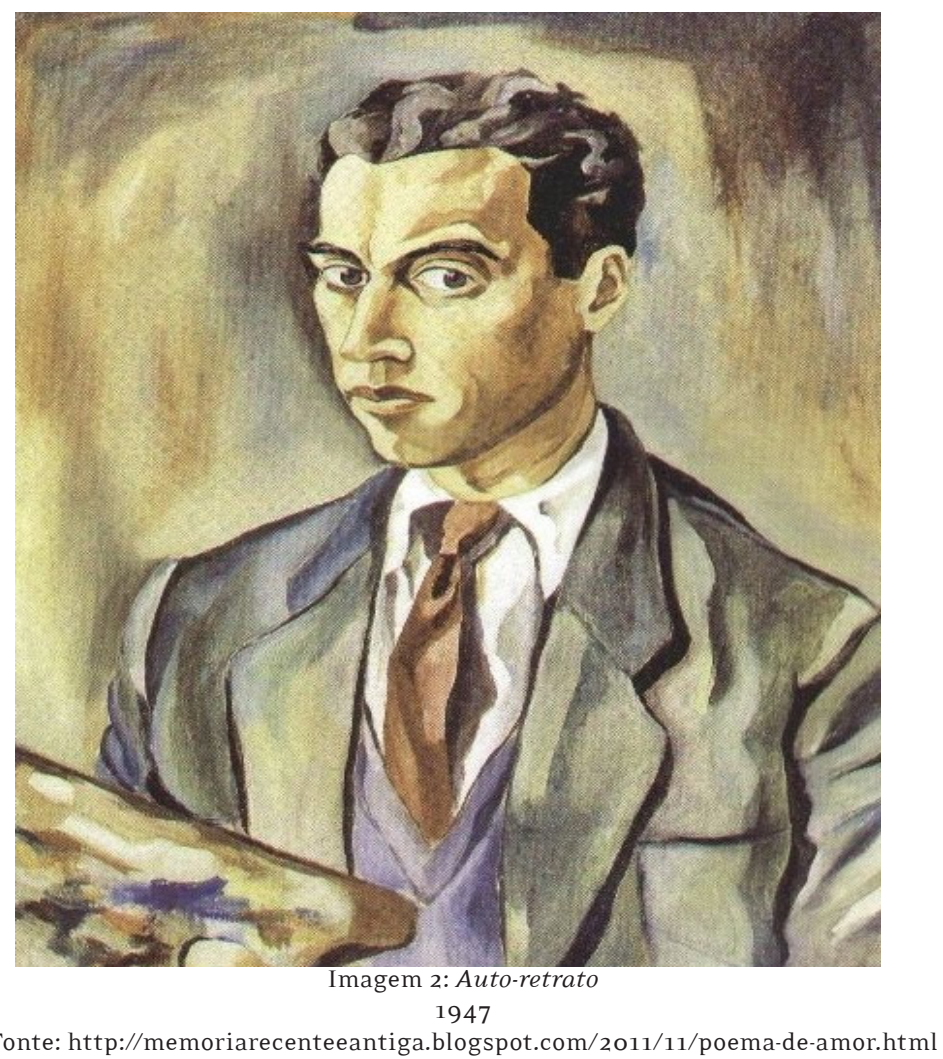


As duas pinturas vêm dos anos 40 do século XX, uma oscilante em termos de datação entre 1944 e 45, outra cravada em 1947: já nos detivemos, como antes afirmado, em cada uma por si, mais o que nos instaram, na sua pregnância, a reflectir; agora colocamo-las frente a frente. Como as duas presenças, a da mulher e a de Fernando Namora, nas respectivas soluções compositivas, se alinham para a esquerda, então, na verdade, apesar de frente a frente, nunca se enfrentariam olhos nos olhos; assim, temos, seja qual for a disposição, uma espécie de perseguição e permanente fuga, algo que inegavelmente escapa. E escapa o feminino ao masculino, assim como vice-versa: o masculino ao feminino; pois não afirma Emmanuel Levinas que o patético do amor é isso? "Dualidade insuperável dos seres: é uma relação com aquilo que se esquiva para sempre” (Levinas 2010: 53).

Entretanto, de acordo com os pares acima enunciados - Estudo/Auto-retrato, feminino/masculino, escultura/pintura, pois Estudo delimita um corpo de mulher e manifesta ostensivamente o sentido escultórico da pintura namoriana, como já vimos em outro lugar (Ferreira 2018: 26) e, pelo seu lado, Auto-retrato trata de fazer uma aproximação identitária de/a Fernando Namora, em que reverbera exemplarmente a lenda fixada por Plínio no que à origem da pintura respeita, ou seja, a recordação de uma ausência; eis que vemos formuladas séries também emparelhadas de pensamento(s).

Como se o feminino fosse resistência e classicismo em face da escorrência expressionista do masculino, introduzindo-nos na difícil relação entre essência e identidade; sobretudo se pensarmos numa identidade em termos modernos, que faz da viagem exploratória o seu paradigma, peregrinação que não chega (quase) nunca ao lugar sagrado e, se o vislumbra, contorce-se o iniciado em dúvida metódica prudente. Em face da alucinação identitária, eis que a mulher parece permanecer como "real" resistente, consistente na sombra da(s) memória(s).

Cabe aqui fazer reparar que existem duas perspectivas diferenciadas de continuidade/descontinuidade: uma subterrânea ou lunar/nocturna, outra aérea ou solar/ diurna. A primeira é feminina e a segunda masculina; a primeira relaciona-se com um caudal de passagem da carne e frisa, simultaneamente, a esperança fundada na família romântica timbrada pela mulher, a mesma que faria renascer a herança dos antigos, por contraponto à decadência cultural; a segunda relaciona-se com o céu das ideias e letras e frisa, simultaneamente, a capacidade disruptiva do saber cumulativo, passível de infirmar as teorias por ele mesmo laboriosamente fabricadas. A primeira é regida pela arte, a segunda pela ciência.

Nestes termos, aparece-nos Estudo para a primeira, como Auto-retrato para a segunda. Repare-se que a mulher de Estudo é um bloco maciço; repare-se que Fernando Namora, em Auto-retrato, é uma experiência, tanto do ponto de vista pictórico, como existencial. 0 que foi certamente exploratório em Estudo, já na obra final, a que se nos dá a ver, assume a permanente postura clássica; o que é a construção de si em Auto-retrato permanece, todavia, em abertura no quadro. A discrepância não deverá 
sobressaltar-nos, no seguinte sentido: é como se Fernando Namora confessasse a sua não capacidade de aceder, por dentro, ao feminino, tornando-o bloco resistente à revelação do mistério que é, afinal, o mistério da própria diferença.

José-Augusto França avisou-nos que o quadro, com a modernidade, foi perdendo os olhos com que fitava o/a espectador/a, tornando-se paulatinamente película ou rio de tinta, aquilo a que chamou "pintura de pintura" (França 1958: 49-50). Todavia, Fernando Namora, em Auto-retrato, olha-nos sem equívocos, fita o/a observador/a em desafio, interpelando, exigindo mesmo, a sua participação na completude da obra. Em Estudo, e diferentemente, uma mulher, que representa na obra pictórica namoriana, sem dúvida, o feminino, ajoelha-se e coloca a sua cabeça à mercê de todo/as nós.

Por tal, será então importante distinguirmos agora a pintura da escultura; como já se manifestou, Estudo está para a escultura, como Auto-retrato o está para a pintura. Uma recuperação imediata da escala valorativa renascentista, em que na pintura avulta cosa mentale e na escultura o árduo trabalho das mãos, poderia bastar para associar a primeira aos écrans projectivos da mente, e a segunda ao corpo presente. Todavia, se a "pintura de pintura”, a mesma que José-Augusto França lamentou ter-se cegado, algo demonstrou, foi exactamente o esforço para se "fazer corpo" e "tornar-se presente". Donde, Fernando Namora, em Auto-retrato, explode na pintura, mostra-se por fora, tanto quanto a mulher, em Estudo, implode em escultura, fixando-se por dentro. Neste sentido, a pintura é agora o reverso, o interior está no exterior; tanto quanto a escultura, pese embora o fazer através da pintura, mantém a opacidade na pele, seja a do próprio quadro, seja a do corpo feminino.

Lembremo-nos, agora da imagem de perseguição e fuga; apenas uma conclusão se afigura possível: feminino e masculino são estranheza e desconcerto, mas também abertura, logo, (re)começo eterno da dança.

\section{Notas}

\footnotetext{
* Cláudia Ferreira é doutorada em Estudos Contemporâneos pela Universidade de Coimbra, mestre em Estudos Sobre a Mulher - As Mulheres na Sociedade e na Cultura pela FCSH da Universidade Nova de Lisboa e licenciada em História/var. História da Arte pela FLUC. Publicou nas Faces de Eva, na Algar, entre outras circunstâncias, escreve na revista Mutante sobre (obras de) arte e deteve-se na "fase negra” de Manuel Filipe.
}

'Cf. Barthes 1987: 7I, nomeadamente quando afirma: "é necessário que o crítico seja justo e que tente reproduzir na sua própria linguagem, segundo ‘uma qualquer encenação espiritual exacta', as condições simbólicas da obra, sem o que não pode, precisamente, ‘respeitá-la”. 
${ }^{2}$ Cf. Agamben 2013: 123.

${ }^{3}$ Cf. Benjamin 1992: I8I, nomeadamente quando afirma: no “domínio da linguagem, só o nome tem esse sentido e significados incomparavelmente elevados: ele é a essência mais íntima da linguagem. 0 nome é aquilo através de que nada mais se comunica e, no qual, a própria linguagem se comunica, em absoluto. No nome, a essência espiritual que se comunica é a linguagem.”

${ }^{4}$ Cf. Pessoa/ Leone/ Rodrigo 1998: 39-57.

${ }^{5}$ Cf. Jacinto 2019.

\section{Bibliografia}

Agamben, Giorgio (2013), A Potência do Pensamento. Ensaios e Conferências, trad. António Guerreiro, Lisboa, Relógio D’Água.

Barthes, Roland (1987), Crítica e Verdade, trad. Madalena da Cruz Ferreira, Lisboa, Edições 70.

Benjamin, Walter (1992), Sobre Arte, Técnica, Linguagem e Política, trad. Maria Luz Moita, Maria Amélia Cruz, Manuel Alberto, Lisboa, Relógio D’Água.

Pessoa, Miguel/ Leone, Palmira/ Rodrigo, Lino (1998), “Caminhos de vida, caminhos de pintura”, in AAVV, Fernando Namora: nome para uma vida, Castelo Branco, Câmara Municipal de Castelo Branco.

Ferreira, Cláudia (2016), “Entre giestas, ruas e retratos: da penumbra”, Algar. Revista de Cultura, Casa Museu Fernando Namora, nO3.

-- (2018), “Do Estudo, ou de como olhar a(s) mulher(es)”, Algar. Revista de Cultura. Casa Museu Fernando Namora, n04/5.

-- (2019), “Auto-retrato”, Algar. Revista de Cultura.,Casa Museu Fernando Namora, n06. França, José-Augusto (1958), Situação da Pintura Ocidental, Lisboa, Edições Ática. Jacinto, Rui (coord.) (2019), Fernando Namora. Itinerário de uma Vida, Geografia de uma Obra, Condeixa-a-Nova, Câmara Municipal de Condeixa.

Levinas, Emmanuel (20ı0), Ética e Infinito, trad. João Gama, Lisboa, Edições 70.

Lisboa, Eugénio (1999), O Objecto Celebrado (Miscelânea de Ensaios, Estudos e Crítica), Coimbra, Universidade de Coimbra.

Miranda, J. A. Bragança de (1998), Traços. Ensaios de crítica de cultura, Lisboa, Vega. 